\title{
Proceeding
}

\section{Superior anthropometric, biomechanical, and psychological indices on kabbadi liver sports athlete performance - a case study: youth National (Kabbadi) team of Islamic Republic of Iran}

\author{
SAEID MOGHADDAM BAGHA ${ }^{1}$, FERESHTEH GOLESTANEH ${ }^{2}$, ELAHE MOEIN ${ }^{3}$ \\ ${ }^{1}$ The supervisor of National Kabbadi Team of Islamic Republic of Iran \\ ${ }^{2}$ Faculty Member of Chabahar Maritime University \\ ${ }^{3}$ Sports Biomechanics, Kharazmi University of Tehran
}

\begin{abstract}
Moghaddam, S., Golestaneh, F., \& Moein, E. (2015). Superior anthropometric, biomechanical, and psychological indices on kabbadi liver sports athlete performance - a Case Study: Youth National (Kabbadi) Team of Islamic Republic of Iran. J. Hum. Sport Exerc., 9(Proc2), pp.S731-S736. The purpose of studies to explore the effect of prior selected anthropometric, biomechanical, psychological indexes on kabbadi sport athlete performance of youth national team of Iran. 100 youth Kabaddi players were selected from national Kabbadi athletes of Iran in 2012-2013. Subjects of the study. Their age ranged between 18 to 22 years. Speed, agility, power, flexibility, background play, femur length, tibia length, the percentage of the body fat and BMI has been selected for this study. The results of study indicates that the average of these factors in national Kabbadi athletes of Iran are, speed (7.07 sec), agility (9.63 sec), power $(0.51 \mathrm{~kg})$, flexibility $(36.57 \mathrm{~cm})$, background play(3 year), percentage of the body fat $(12.94)$ and BMI $(23.92 \mathrm{~kg} / \mathrm{m} 2)$. Among the mentioned variables, agility and background play have the most and the variable of flexibility has the less impact on players' performance. Keywords: KABBADI, PERFORMANCE, ANTHROPOMETRIC, BIOMECHANICAL, PSYCHOLOGICAL.
\end{abstract}

Corresponding author. The supervisor of National Kabbadi Team of Islamic Republic of Iran.

Asia Pacific Conference on Performance Analysis of Sport, 21-24 April 2014. Langkawi, Malaysia.

JOURNAL OF HUMAN SPORT \& EXERCISE ISSN 1988-5202

(c) Faculty of Education. University of Alicante

doi:10.14198/jhse.2015.10.Proc2.13 


\section{INTRODUCTION}

Kabaddi is a one of traditional games in Iran, played until he takes another breath. If the raider cannot return to by thousands of people in cities and villages. This game his court in the same breath while chanting 'kabaddi', he has different names in various parts of Iran. For example, will be declared out. Each team alternates in sending is called Shirindudu in Gilan, Khorasan, Golestan and player into the opponents' court. If a player goes out of Mazandaran, Zou, Khuzestan Eshtiti and in Sistan and the boundary line during the course of the play, or if any Baluchestan is called Kabaddi. (3).

Kabaddi is a combative team game, played on a rectangular court, either out-doors or indoors with seven players on the ground for each side. Each side takes alternate chances of offence and defense. The basic idea of the game is to score points by raiding into the opponents' court and touching as many defense players as possible without getting caught on a single breath. During play, the players on the defensive side are called "Antis" while the player of the offense is called the "Raider". Kabaddi is perhaps the only combative sport in which attack is an individual attempt while defense is a group effort. The attack in Kabaddi is known as a 'Raid'. The antis touched by the raider during the attack are declared 'out' if they do not succeed in catching, the raider before he returns to home court. These players can resume play only when their side scores points against the opposite side during their raiding turn or if the remaining players succeed in catching the opponent's raider. The game calls for agility, good lung capacity, muscular coordination, presence of mind and quick responses. For a single player to take on seven opponents is no mean task, requires dare as well as an ability to concentrate and anticipate the opponent's moves.

\section{ANALYSIS OF TECHNIQUES OF KABADDI}

Raid

The raid is of a complex nature and several factors are to be considered to make it successful. A good raider should have the skill, tactics, counter-action ability to extricate himself from difficult situations, and above all, good footwork to score points. A combination of all these factors, with an ability to make spot judgments of the situation will make the player a top class raider. We shall now go into the structure of a raid and the different steps associated with it, to understand the raid and its constituents.

\section{Cant}

One of the unique features of Kabaddi is the cant. The raider has to withhold his breath during the entire course of the raid and keep up a continuous and audible chant of the word Kabaddi until he returns to home court. This is known as cant in Kabaddi and if he happens to lose his cant during the raid or struggle before he reaches home court, he will be declared out and the offense side will lose a point. The definition of cant as coined by the Amateur Kabaddi Federation of India rules reads 'The repeated without break and at a stretch and clear utterance of the approved word "Kabaddi" within the course of one respiration shall be called a cant'. In other words, cannot also be defined as the i-measurement of raid since the length of the raid can be determined on the duration of cant.

Settling \& path of attack

Settling means getting set before an attack. Normally, after entry into the opponent's court, the raider takes a few seconds to study the situation and decide upon the path of attack. In these few seconds, he chooses a target and makes his moves accordingly. If he does not get set but charges blindly into the opponent's court, there is more likelihood of his being caught. For example, in pursuit, when the raider charges without getting set, he exposes himself to the risk of being caught, since he does not take time to plan the path of 
attack or think of the consequence of his moves. The raider must take care not to go too deep into the opponent's court or be surrounded by the antis. He must also plan his path of retreat to home court. He must invariably select a path to the centerline for retreat after attack, for which he may choose to turn, go outside, or take a side ward movement.

\section{Footwork}

Footwork in Kabaddi means the movements made by the raider with his feet, during the course of the raid. The factors influencing footwork include the stance of the raider, body position, movement, speed, agility, etc. A raider has to move quickly from one spot to the other during raid, complete his task and reach home safe. For this he depends largely on footwork. Footwork can broadly be classified into four types, i.e. Leading Leg Raid, Shuffling Raid, Natural Method and Reverse Step Raid, which will be gone into in detail in the chapter on basic offense skills.

\section{Skills}

Skill is the automatic application of technique without conscious thought. Skill can also be defined as the ability to co-ordinate different muscles in order to perform a combination of specific movements smoothly and effectively. Technique should be applied with dexterity, economy of movement and easily, without tension. Mastery over the techniques of the game is called skill. The skills used by the raider in Kabaddi are called- offensive skills, while the skills used by the antis are called defensive skills. During raid, the raider has to make maximum use of his limbs to come in contact or touch the opponents in order to score points. This is accomplished through leg touches such as toe touch, foot touch, squat leg, thrust, kicks etc, with lower limbs and through hand touches with upper limbs.

Apart from these basic skills, the raider must also learn advanced skills, such as counter action for escape from different holds. A skilful raider is one who has gained mastery over all these techniques.

Tactics

Tactics means exploiting a given situation to one's advantage or creating a situation to suit one's purpose.

In Kabaddi, the raider is the principal performer who can change the tempo of the game. Depending on the game situation, the raider may increase or decrease the tempo of the game. In order to do this he may adopt a passive raid or an aggressive raid by creating a situation for a struggle. Sometimes the raider may pass time in the last few minutes of the game, especially when his team is leading and the opponents are playing an aggressive game. All these are the tactics adopted by the raider keeping in view the game situation. Tactics and techniques go hand in hand for any successful raid.

\section{Retreat}

Unless the raider returns to home court, safely after. The raid, the raid cannot be treated as successful. This is called retreat. The raider has to pre-plan his path of retreat before starting his raid. While retreating to home court, the raider should keep the following points in view. (1).

Athletic performance in kabaddi is a function of needs a small playing area and no special equipment is aerobic fitness, anaerobic fitness, dynamic balance, required. The kabaddi playing area is $13 \mathrm{~m} \times 10 \mathrm{~m}$, divided agility, individual proficiency, neuromuscular by a line into two halves. The side winning the toss sends coordination, lung capacity, quick reflexes, intelligence a 'raider', who enters the opponents' court chanting, and presence of mind on the part of both attackers and 'kabaddi-kabaddi'. The raider's aim is to touch any or all defenders [2]. During a match a player frequently performs players on the opposing side 
and return to his court in activities that require rapid development of force, such as one breath. The person, who the raider touches, will reaction and quickly changing direction.

Kabaddi is a game which combines the actions of Data Collection: The following are the proposed variables wrestling, judo, rugby and gymnastics. The important for the proposed study: body movements in this game involve catching, holding, locking and jumping, thus the possession of desirable Anthropological Components: anthropometric and physiological characteristics will have a greater advantage in executing a better performance in Height competition [2]. There are a few biomechanical and Height leg physiological studies on kabaddi players on national or sitting height international players.

\section{PROCEDURE AND METHODOLOGY}

Selection of Subjects for the present study 100 Kabaddi players were selected randomly as the subjects from national Kabbadi athletes of Iran. Their age ranged from 18 to 22 years.

Data Collection: The following are the proposed variables for the proposed study:

1- Anthropological Components: height, weight, upper and lower body height, leg length, length of hip, thigh, calf circumference, and BMI and body fat percentage.

Body Fat Percentage: Subcutaneous body fat was measured at 3 sites (chest, abdominal and thigh) caliper. Body fat percent was computed through the formula developed by Jackson and Pollock [6, 7] and grip strength (GS) was measured by Hand Dynamometer (4).

2- Physical Fitness Components: speed, agility, power, flexibility.

Speed was measured by administering 50 yard dash and the performance was recorded in second (5).

To determine the agility was used and the reading was recorded in seconds.

Statistics: Descriptive information was based on information gathered from the tests. Mean (M) and standard deviation (SD) were used to describe data.

\section{RESULTS}

Table 1. Main characteristics of subjects (mean \pm SD)

\begin{tabular}{lc}
\hline BMI & \\
\hline FP\% & $23.929 \pm 1.039$ \\
Sitting height $(\mathrm{cm})$ & $12.945 \pm 6.941$ \\
Weight $(\mathrm{kg})$ & $89 \pm 2.582$ \\
Height $(\mathrm{cm})$ & $72.909 \pm 8.320$ \\
Age $($ years $)$ & $175.476 \pm 8.177$
\end{tabular}




$\begin{array}{lr}\text { Upper body height } & 20.286 \pm 1.271 \\ \text { Lower body height } & 88.833 \pm 2.787 \\ \text { Length of hip } & 97.167 \pm 7.195 \\ \text { Thigh } & 44.167 \pm 4.956 \\ \text { Leg length } & 51.333 \pm 4.033 \\ \text { Calf circumference } & 44.333 \pm 5.785 \\ \text { Total arm length } & 34.333 \pm 3.445 \\ & 169.714 \pm 7.111\end{array}$

Table 2. Agility test, speed, power, flexibility (mean \pm SD)

\begin{tabular}{lc}
\hline Agility & $9.63 \pm 0.702$ \\
Speed & $7.704 \pm 0.473$ \\
Power & $0.514 \pm 0.075$ \\
Flexibility & $36.571 \pm 5.769$ \\
\hline
\end{tabular}

\section{DISCUSSION AND CONCLUSION}

Three coach of Kabbadi who have observed the subjects' practices and aware of them properly, get subjects' performance quantitative scores from 0 to 100 . The mean score were considered as individual performance. To predict the performance, the independent variables, and to predict the design of equation for Kabbadi athlete's performance, multiple regressions were used for statistical analysis.

It can be concluded that experience, background play, agility, femur length, and flexibility skills are important in achieving success in Kabbadi. It is essential to consider these factors to achieve maximum success in the field and select the best players.

The findings of the present study demonstrated that there is a significant relationship betwee $4 \mathrm{n}$ variables of the short distances between speed, power, agility, flexibility, background play, femur length, tibia length, the percentage of the body fat, agility, and BMI and successful performance. Among the mentioned variables, agility and background play have the most and the variable of flexibility has the less impact on players' performance.

As the next step the research team will study the effective factors in performing Kabbadi skills at high standards. The study team proposes the next step to be carried out via comparative study of various national teams. The next step will also propose practical methods in order to talent scout for Kabbadi. 


\section{REFERENCES}

1. Afims, A.K., Dasgupta, P.K., Panda, B.K., \& Bhattacharya, A.K. (1982). Physical efficiency tests on indian male "kabaddi" inter-university players. British Journal of Sports Medicine, 16(1), pp.33-36.

2. Aminian Razavi, T., Shabkhiz, F., Amirshaghaghi, F., \& Abdollahi, R. (2012). Comparing the Effect of Faradic and Aerobic Exercise on Circumference, \% Fat and Endurance of Abdomen in NonAthlete Women. World Journal of Sport Sciences, 6(4), pp.367-371.

3. Dey, S.K., Khanna, G.L., \& Batra, M. (1993). Morphological and physiological studies on Indian national kabaddi players. British Journal of Sports Medicine, 27(4), pp.237-242.

4. Federation, I.K. (2012). Rules and regulations of kabaddi. http://www.sikhwomen.com/ Community/ India/kabaddi/how_to_play_kabaddi.htm.

5. Jackson, A., \& Pollock, M. (1978). Generalized equations for predicting body density of men. British Journal of Nutrition, 40(3), pp.497-504.

6. Majlesi, M., Azadianand, R., \& Rashedi, H. (2012). Correlation Between Anthropometric and Physical Fitness Traits: A Case Study in Hamedan Kabaddi Team. World Journal of Sport Sciences, 7(4), pp.181-184.

7. Verma, A., Devpal, R., \& Abhimanyu, S. (2011). To develop physical profile of kabaddi players: the descriptive study. Indian Journal of Movement Education and Exercises Sciences (IJMEES). 